\begin{tabular}{|c|c|c|}
\hline & Int.J.Curr.Microbiol.App.Sci (2021) 10(11): 294-305 & \\
\hline$\frac{}{\text { EXCELLENT }}$ & $\begin{array}{l}\text { International Journal of Current Microbiology and Applied Sciences } \\
\text { ISSN: 2319-7706 Volume } 10 \text { Number } \mathbf{1 1} \text { (2021) } \\
\text { Journal homepage: http://www.ijcmas.com }\end{array}$ & PO \\
\hline PUBLISHERS & & wwww.jicmas.com \\
\hline
\end{tabular}

\title{
Co-Carcinogenicity of Arsenic: Probable Mechanisms
}

\author{
Archismaan Ghosh, Sutapa Mukherjee and Madhumita Roy ${ }^{*}$ \\ Department of Environmental Carcinogenesis \& Toxicology, Chittaranjan National Cancer \\ Institute, 37, S P Mukherjee Road, Kolkata 700026, India \\ *Corresponding author
}

\section{A B S T R A C T}

\section{Keywords}

Arsenic, cocarcinogenicity, DMBA, ROS, inflammation

Article Info

Received:

12 October 2021

Accepted:

05 November 2021

Available Online:

10 November 2021
Presence of carcinogens, like Polycyclic Aromatic Hydrocarbons (PAH), in the form of cigarette smoke, vehicular emission and industrial emissions in our immediate surroundings is a potent health hazard. Arsenic, a carcinogenic metalloid, omnipresent in the environment, can act as co-carcinogen, where it enhances the carcinogenicity of other carcinogens. In the present study, the co-carcinogenic effect of Arsenic has been investigated, upon the 7,12-dimethylbenz[a]-anthracene (DMBA), a PAH, induced skin cancer model, in Swiss albino mice. Histological analysis revealed earlier development of invasive carcinoma in the DMBA and arsenic treated group in comparison to the DMBA treated mice alone. To understand this phenomena, ROS generation, DNA damage, lipid peroxidation, protein carbonyl content, total antioxidant capacity and activity of pro-inflammatory cytokines (TNF- $\alpha$, IL6, IL17a, IL22) and their downstream modulators (NF- $\mathrm{\kappa B}$ ) was assessed. The results suggested that arsenic in the presence of DMBA induced higher ROS generation, greater DNA damage, elevated lipid peroxidation, increased protein carbonyl content, upregulated activity of pro-inflammatory cytokines and their downstream regulators as well as down regulated the total antioxidant capacity in comparison to DMBA alone. These findings hint at the co-carcinogenic potential of arsenic, as it significantly enhances the carcinogenicity of DMBA and hastens carcinogenesis.

\section{Introduction}

The present external condition of an individual which influences its development and growth, is generally referred to as its environment (Belpomme et al., 2007). Research has shown that environmental factors play an important role in development of cancers (Rushton et al., 2003). There are numerous cancer-causing environmental factors to which we are exposed. Amongst these factors, Polycyclic Aromatic Hydrocarbons (PAH) are notable, which are often present in our immediate surroundings (Lawal, 2017). These are a group of very potent carcinogens, as evident from epidemiological and animal studies. PAHs, can attach to fine carbon particles and remain suspended in air. They are produced due to combustion of organic substances and are found in factory and cigarette smoke, waste 
emissions and vehicular emissions (Siddens et al., 2012). Exposure to these unavoidable pollutants often lead to cancer. Presence of heavy metals/metalloids also act as environmental carcinogens. Arsenic is a good example of such a contaminant which may enter our body through air, water and soil. Arsenic is well recognised as a cancer-causing agent, as it has been enlisted in the class 1 group of carcinogens by IARC (Howe and Gamble, 2016). High concentrations of inorganic arsenic (iAs) in groundwater is a major problem in many countries. Unsuspected exposure to this agent often occurs due to its colourlessness, tastelessness and odourlessness. As a result, more than 200 million people worldwide are exposed to it (Howe and Gamble, 2016). There are many studies which state that chronic exposure of inorganic iAs leads to cancer of numerous organs. Presence of iAs enhances the carcinogenicity of other carcinogens to which we are exposed, rendering it as a cocarcinogen.

There are very few reports on the cocarcinogenic effect of iAs upon consumption of tobacco, but studies have reported that iAs increases the carcinogenic potential of cigarette smoke hence incidences of cancer (Hays et al., 2006). The ability of iAs to induce and maintain chronic inflammatory conditions defines the enhanced carcinogenicity of the co-exposure of iAs and cigarette smoke (Kinnula, 2005). These persistent inflammatory conditions illicit excess oxidative stress generation, which ultimately results into cells acquiring neoplastic ability (Yao et al., 2005). Excess oxidative stress generation promotes and initiates carcinogenesis by directly activating procarcinogens e.g. Benzopyrene (Hays et al., 2006). They also lead to oxidative damage of DNA, lipids and proteins (Hayes et al., 2020). Compromised activity of antioxidative enzymes, which has been observed upon iAs administration, can also lead to greater accumulation of oxidative radicles (Mittal and Flora, 2006). A study has also reported increased DNA damage due to co-exposure of iAs and cigarette smoke (Hughes, 2002). A recent study on the tobacco chewing population of Assam, revealed that, tobacco consumers from iAs endemic regions had shown severe upregulation of cell's proliferative and genotoxic markers in comparison to other groups of individuals who were only exposed to only one of the carcinogens (Roy et al., 2016). This finding points out the co-carcinogenic nature of iAs where it enhances the carcinogenicity of the cigarette smoke and leads to early cancer development. A study upon Syrian hamster mice also reported that, cigarette smoke in the presence of iAs, leads to much higher ROS generation and oxidative DNA damage in the lungs of the mice in comparison to that generated individually by iAs and cigarette smoke (Hays et al., 2006).

The toxic pyrolytic products of cigarette smoke and the metabolites of iAs metabolism are quite efficient in induction of inflammatory cells like macrophages, neutrophils and eosinophils which further induce secretion of cytokines and generate ROS (Godschalk et al., 2002). Cytokine like TNF- $\alpha$ play an important role in the activation of inflammatory cells as well as induction of other pro-inflammatory cytokines like IL-6 etc (Rao et al., 2017). The excess ROS generated during this process proceeds to damage the cell membrane via lipid-peroxidation as well as damaged proteins by formation of protein carbonyls. Reduction in the activity of antioxidant enzymes further helps in accumulation of these damages which ultimately promote carcinogenesis (Samuel et al., 2005).

The present study aims to elucidate the mechanism of co-carcinogenicity of iAs upon 
the 7,12-dimethylbenz[a]-anthracene (DMBA) and 12-O-tetradecanoylphorbol-13-acetate (TPA) model of skin carcinogenesis. DMBA is PAH which has been used as a prominent carcinogen initiator in many animal models whereas TPA acts as a promoter.

\section{Materials and Methods}

\section{Animal maintenance}

The present work was carried out in male Swiss Albino mice (Mus musculus), 4-5 weeks old, bred in the animal house of Chittaranjan National Cancer Institute. Institutional Animal ethics Committee (vide IAEC 1774/MR3/2017/9) had granted the permission of this animal experimentation. Mice were maintained at a constant temperature of $22 \pm 2^{\circ} \mathrm{C}$ and were exposed to 12 hours of light and darkness. Synthetic pellets were given to the mice as food and water was provided $a d$ libitium.

\section{Animal treatment}

The mice were divided into three groups namely: Control, DMBA and DMBA + iAs. Each group had 10 mice with 5 mice being present in each cage. All the mice were shaved in their hind region. The mice belonging to the control group did not receive any treatment. They were fed normal tap water and mouse feed.

The mice belonging to the DMBA group were painted with $1 \mathrm{mg} / \mathrm{ml}$ concentration of DMBA in acetone, in the shaved region of their skin once, followed by painting with croton oil twice weekly. The mice belonging to the DMBA + iAs group received the DMBA and croton oil treatment as mentioned above, along with iAs. $500 \mu \mathrm{g} / \mathrm{l}$ concentration of sodium arsenite was administered to the mice in drinking water as well as by painting on their shaved region.
Histological analysis to confirm the development of cancer

Tissues and skin lesions, isolated at different time points from the mice, were washed in normal saline and fixed in 10\% Neutral Buffered Formalin (NBF) overnight. Dehydration and fat removal were done by treating the tissues with increasing grades of alcohol $(50 \%, 70 \%, 90 \%$ and 100\%) and xylene. Tissues were then embedded in paraffin blocks. Microtome was used to section these blocks into $4 \mu \mathrm{m}$ thick sections which were then stretched on glass slides and were stained with Haematoxylin and Eosin. They were then mounted with DPX and observed under light microscope. Haematoxylin stained the nucleus blue while Eosin stained the cytoplasm pink.

\section{Estimation of ROS generation}

Generation of ROS was estimated following the protocol of Balasubramanyam et al., (Balasubramanyam et al., 2003). with slight modifications. ROS was estimated in the leukocytes of the mice isolated from the blood. Isolation of leukocytes was done using Solution A (NH4Cl dissolved in TRIS at $\mathrm{pH}$ 7.2) and Solution B (mesoinositol) and then they were suspended in HBS (Hepes Buffered Saline $\mathrm{pH}$ 7.4). $10 \mathrm{mM}$ of $2^{\prime}, 7^{\prime}$ dichlorodihydro- fluorescein (DCFH-DA) was added to the leukocytes suspended in HBS and was incubated for 45 minutes in darkness. The fluorescent intensity of the samples was then measured at $530 \mathrm{~nm}$ using a Varian Cary Eclipse Fluorescence Spectrophotometer.

\section{Estimation of DNA damage using Single Cell Gel Electrophoresis}

DNA damage was estimated by Single Cell Gel Electrophoresis Assay, also known as the Comet Assay, performed according to Singh et al., (Singh et al., 1988). 
$20 \mu 1$ of isolated mice leukocytes were mixed in $0.6 \%$ low melting agarose and spread over frosted slides which were already coated with $0.75 \%$ of normal melting agarose. The cells were lysed overnight, at $4^{\circ} \mathrm{C}$ by immersing the slides in lysis buffer $(2.5 \mathrm{M} \mathrm{NaCl}, 0.1 \mathrm{M}$ Na2EDTA, $10 \mathrm{mM}$ TRIS, $0.3 \mathrm{M} \mathrm{NaOH}$, $10 \%$ DMSO and $1 \%$ TritonX; $\mathrm{pH} 10$ ). The slides were then soaked in electrophoresis buffer (10 mM NaOH, $0.2 \mathrm{~m} \mathrm{Na}$ - EDTA; $\mathrm{pH}>13$ ) for 20 minutes before performing electrophoresis. Thereafter electrophoresis was performed for 25 minutes at $15 \mathrm{~V}$ and $220 \mathrm{~mA}$ current. The slides were then stained with ethidium bromide and observed under fluorescent microscope.

\section{Estimation of lipid damage following Lipid Peroxidation Assay}

Cell membrane damage due to ROS generation was assessed using lipid peroxidation assay. Lipid peroxidation was performed following the protocol of Okhawa et al., (Okhawa et al., 1979). The isolated animal tissues were homogenised followed by addition of $20 \%$ Acetic acid, 10\% SDS and $0.8 \%$ TBA.

For 1 hour this mixture was kept in boiling water followed by immediate transfer to ice for 10 minutes. Centrifugation was performed at $2500 \mathrm{rpm}$ for 10 minutes followed by collection of the supernatant and observation of its OD at 535nm. The extent of lipid peroxidation was estimated by calculating the mole of Malondialdehyde (MDA) generated.

\section{Estimation of protein carbonyl formation}

Protein carbonyl content was estimated colorimetrically by Protein Carbonyl Assay Kit by Cayman Chemicals (10005020). Formation of Schiff's base in the tissue homogenate by 2,4-Dinitrophenylhydrazine (DNPH) due to the presence of protein carbonyl was spectrophotometrically detected at $360-385 \mathrm{~nm}$.

\section{Estimation of total antioxidant capacity}

Antioxidant Assay Kit (709001) manufactured by Cayman Chemicals was used to measure colorimetrically the total antioxidant capacity.

The antioxidant capacity of the samples was estimated by their ability to prevent the oxidation of ABTS [2,2'-Azino-di-(3ethylbenzthiazoline sulphate)].

Antioxidative capacity of the antioxidants in the sample was compared to that against Trolox (tocopherol analogue), which is the standard. The absorbance of the final oxidative product of ABTS was measured spectrophotometrically at $405 \mathrm{~nm}$.

\section{Cytokine detection assay}

The activities of TNF- $\alpha$, IL-6, IL-17A, IL-22, along with two subunits of $\mathrm{NF}-\kappa \mathrm{B}, \mathrm{p} 50$ and p65 were measured in the serum of the mice using TNF alpha ELISA Kit (ab208348), IL-6 ELISA Kit (ab100712), IL-17A ELISA Kit (ab199081), IL-22 ELISA Kit (ab223857), NF- $\kappa \mathrm{B}$ p50 Transcription Factor Assay Kit (ab207217) and NF- $\kappa$ B p65 ELISA Kit (ab176648) respectively, manufactured by Abcam. The assays were performed according to manufacturer's protocol utilising sandwich ELISA technique. The OD of the endpoint was measured at $450 \mathrm{~nm}$.

\section{Statistical analysis}

Graph Pad Prism Software was used to perform statistical analysis. The groups were compared using ANOVA followed by student's t-test. Significance level of $\mathrm{p}<0.005$ was taken to be significant while $\mathrm{p}<0.0001$ was considered to be highly significant. 


\section{Results and Discussion}

Development of skin carcinogenesis and its confirmation by histological analysis

Histological analysis of the skin tissue and lesions of the DMBA treated mice revealed development of hyperplasia, dysplasia, in-situ carcinoma and invasive carcinoma at 60, 120, 240 and 300 days respectively. The DMBA+As treated mice tissues had developed severe dysplasia at 60 days of treatment, in-situ carcinoma at 120 days and invasive carcinoma at 240 days. The carcinogenic and aggressive histological changes which were visible in the DMBA treated mice only after 300 days of treatment were achieved at 240 days of treatment in presence of iAs. This result highlights the cocarcinogenic potential of iAs where it enhances the carcinogenicity of DMBA, by early development of invasive carcinoma, as assessed by the histological analysis done by hematoxylin and eosin staining.

\section{Estimation of excess ROS generation}

ROS generation was measured as changes in the fluorescence intensity in the leukocytes of the mice and were recorded at different time intervals $(0,60,120,240,300$ days). The line graph in figure $2 \mathrm{~A}$ represents the mean fluorescence intensities of three independent experiments. ROS generation was significantly higher $(\mathrm{p}<0.0001)$ in the DMBA+As group than the DMBA group alone. The ROS generated at 240 days in $\mathrm{DMBA}+\mathrm{As}$ group was higher than the amount generated at 300 days in the DMBA group which may be the cause of early development of carcinoma in the DMBA+As group.

\section{Estimation of DNA damage}

DNA damage was estimated by Single Cell Gel Electrophoresis or Comet assay which results in the formation of comet tail like pattern of the damaged DNA. Damage was expressed in terms of Olive tail moment (OTM) which is calculated as the product of comet tail length and the percentage of DNA present in it. The OTM of the three groups of mice were recorded at different time intervals (0, 60, 120, 240, 300 days) and results thus obtained were represented using a line graph (figure 2B). DMBA+As group had significantly higher $(\mathrm{p}<0.0001)$ OTM at 240 and 300 days in comparison to the DMBA group. The OTM of the DMBA+As group at 240 days was nearly double of its DMBA counterpart, indicating that the cocarcinogenic effect of iAs enhanced the damage to DNA. This evidence supports the histological findings where early development of invasive carcinoma was observed in the DMBA+As group with respect to the DMBA group.

\section{Estimation of membrane damage by lipid peroxidation assay}

The moles of MDA generated by the different groups of mice has been represented statistically in a linear graph in figure $2 \mathrm{C}$.

Significantly higher $(\mathrm{p}<0.0001) \quad$ MDA generation was observed in the DMBA+As group of mice at 120, 240 and 300 days of treatment compared to DMBA group.

The moles of MDA generated at 240 days, in the DMBA+As group, is much higher than the amount of MDA which is generated by the DMBA treatment alone even at 300 days.

This finding further supports the other results where it has been observed that, DMBA along with iAs hastens the induction of invasive carcinoma compared to DMBA alone. Greater induction of lipid peroxidation inducing early carcinogenesis defines the co-carcinogenicity of iAs. 
Estimation of protein damage by protein carbonyl formation

Protein carbonyl content were shown in figure 2D. Higher protein carbonyl formation was observed in the DMBA+As group than the DMBA group. The protein carbonyl content at 240 days in the DMBA+As group was higher than its DMBA counterpart at 300 days. This high protein carbonyl content of DMBA+As group indicates severe protein damage and this could contribute to carcinogenicity at an earlier time.

\section{Estimation of total antioxidant capacity}

Results of the total antioxidative capacity, as measured by Trolox equivalent has been depicted as a line graph in the figure 3 . The total antioxidation capacity decreased in both the DMBA and DMBA+As groups with increasing time intervals of 60,120, 240 and 300 days respectively. However, at a particular time point, decrease in the DMBA+As group was much greater than that observed in the DMBA group. The antioxidative capacity of the DMBA + As group at 120 and 240 days of exposure was lesser than that of the DMBA group at 240 days and 300 days respectively. Presence of As diminishes the Trolox equivalent value further, indicating co-carcinogenicity of As.

Estimation of the activity of the proinflammatory cytokines TNF- $\alpha$, IL6, IL17a and IL22 along with the two subunits of NF- $\kappa B$ i.e. p50 and p65

The activity of the pro-inflammatory cytokines and the two subunits of NF- $\mathrm{BB}$ (p50, p65) has been depicted as a bar graphs in figure 4. The activity of TNF- $\alpha, \mathrm{p} 50$, p65, IL6, IL17a and IL22 was found to be significantly high $(\mathrm{p}<0.0001)$ in the DMBA+As mice, in comparison to the DMBA group. This is particularly so at 240 and 300 days. At 240 days of treatment, the activity of these cytokines and transcription factors was found to be much higher in the DMBA+As group with respect to the values at 300 days of exposure of the DMBA group. This result highlights that iAs increases the carcinogenicity of DMBA by greatly upregulating the activity of pro-inflammatory cytokines and their downstream transcription factors, which ultimately facilitate early development of invasive carcinoma.

The two-step model of skin carcinogenesis using DMBA and TPA, is a standard mouse skin cancer model (Abel et al., 2009). The present study is aimed at investigating the cocarcinogenic potential of iAs, where it enhances the carcinogenicity of other carcinogens. From the histological analysis it was inferred that groups of mice which received the treatment of DMBA and iAs together, developed in-situ and invasive carcinoma much earlier than those which received only DMBA. This early development of cancer upon combined treatment of DMBA and iAs may be due to the co-carcinogenic ability of iAs. Therefore, elucidation of the mechanism of co-carcinogenicity of iAs is very important.

Generation of ROS leads to a plethora of events, which may lead to carcinogenicity. Excess ROS generation has serious implications at the cellular and genetic level.

Damage to DNA, protein and lipid may be facilitated due to ROS. Accumulation of these damages promote carcinogenesis. Reports have stated that iAs can induce generation of oxidative stress both in vivo and in-vitro, which contribute to cancer development (Roy et al., 2008; Sinha et al., 2010). Formation of DNA adducts and strand breaks is one of the major targets of ROS (Roy et al., 2011). 
Fig.1 Histopathological studies during development of carcinogenesis at different time. Tissue sections were stained by $\mathrm{H} \& \mathrm{E}$ and visualised under a light microscope. Histological analysis reveals development of hyperplasia, dysplasia, in-situ carcinoma and invasive carcinoma at 60,120, 240 and 300 days respectively for DMBA treated group. For DMBA+iAs treated group, at 60, 120 and 240 days respectively dysplasia, in-situ carcinoma and invasive carcinoma were observed.

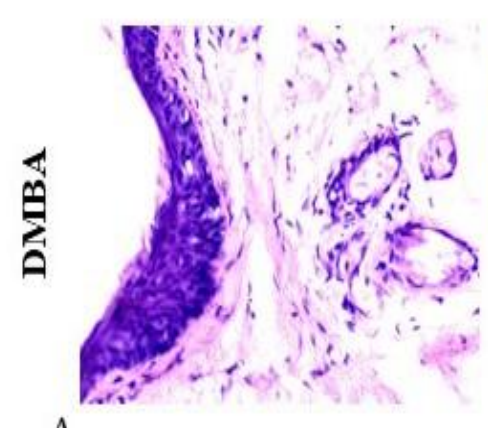

A

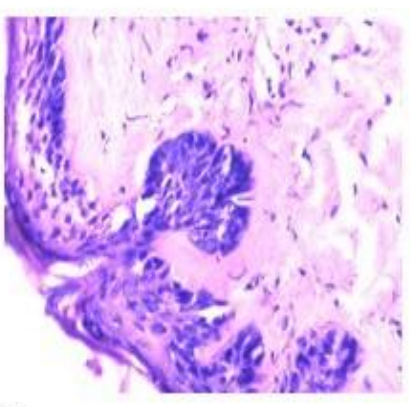

B

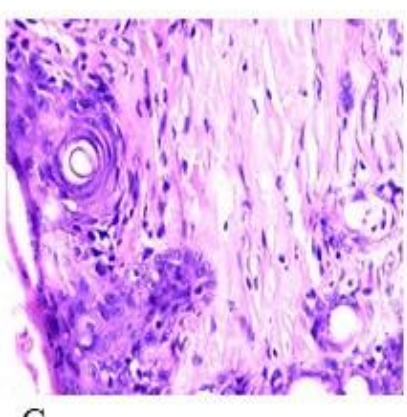

C

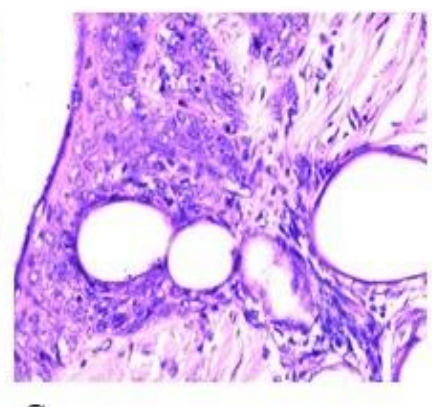

G

60 DAYS
120 DAYS

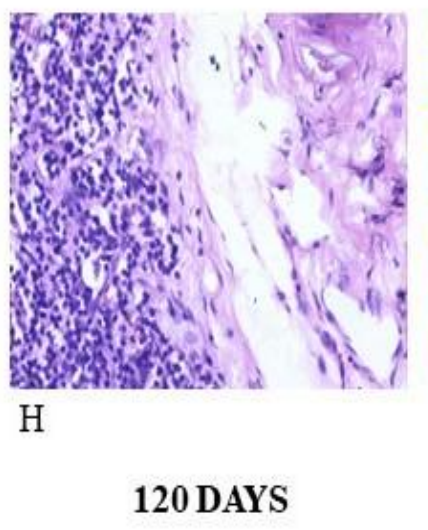

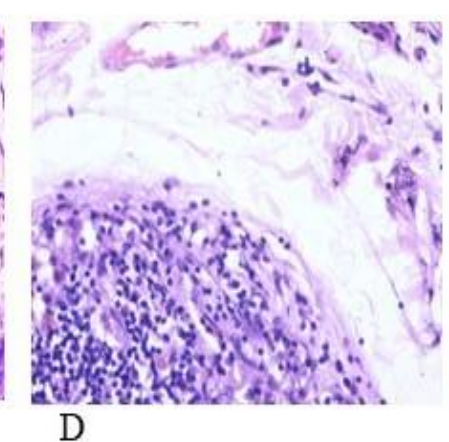

D

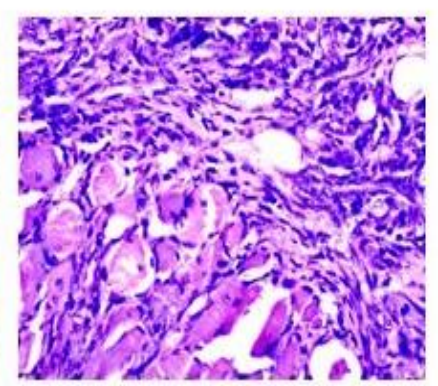

I

240 DAYS

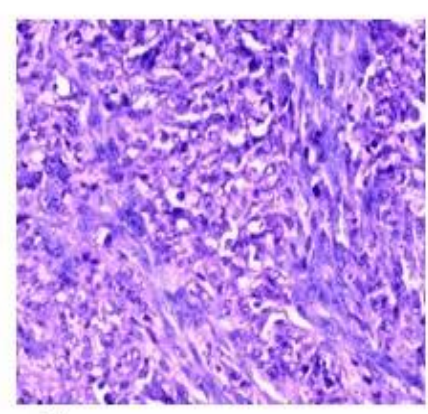

E

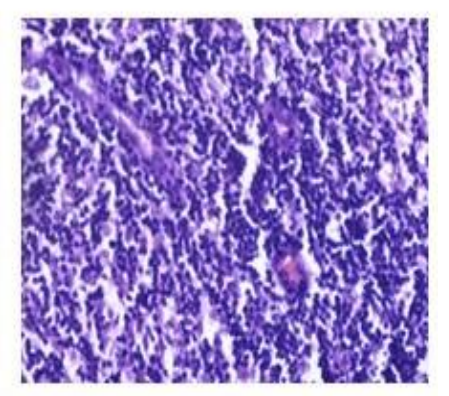

J

300 DAYS

Figure 1 
Fig.2 Effect of DMBA, alone or in conjunction with iAs at the cellular level. (A) Generation of ROS as estimated by spectrofluorimeter after staining with DCF-HDA. (B) DNA damage by DMBA (alone or in presence of iAs) as assessed by OTM. On an average 200 cells were scored per point. (C) Induction of lipid damage by DMBA and DMBA+iAs, as assessed by lipid peroxidation assay by calculating the moles of malondialdehyde. (D) Assessment of protein damage by DMBA, alone or in cooperation with iAs, as assessed by formation of protein carbonyl. Data points are mean of three independent experiments. High level of ROS, OTM, LPO and Protein carbonyl by DMBA is significant with respect to control at ${ }^{\mathrm{a}} \mathrm{p}<0.0001$ and ${ }^{\mathrm{b}} \mathrm{p}<0.005$. Presence of iAs enhances these effects further, which is significant at ${ }^{*} \mathrm{p}<0.0001$ and ${ }^{* *} \mathrm{p}<0.005$.
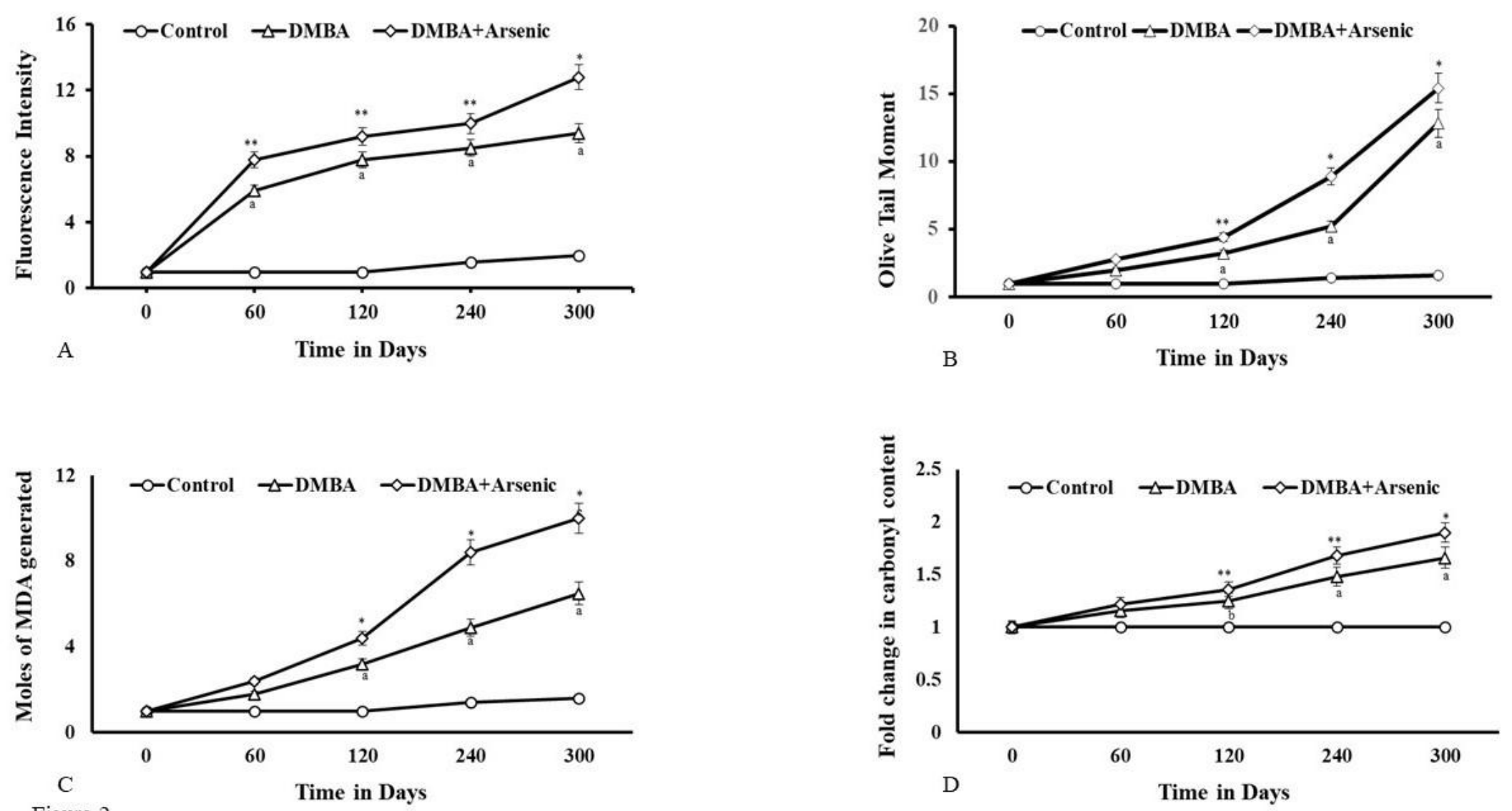
Fig.3 Antioxidant capacity as affected by DMBA and iAs. Total antioxidant capacity was determined by Trolox antioxidant assay. Trolox antioxidant activity is the mean of three independent experiments. Data are shown as mean \pm SD. Antioxidant capacity have been found to be reduced significantly with respect to the control, at ${ }^{a} \mathrm{p}<0.0001 ;{ }^{b} \mathrm{p}<0.005$. Greater reduction in Trolox equivalent value has been observed in presence of iAs, which is significant at $\mathrm{p}<0.0001,{ }^{* *} \mathrm{p}<.005$.

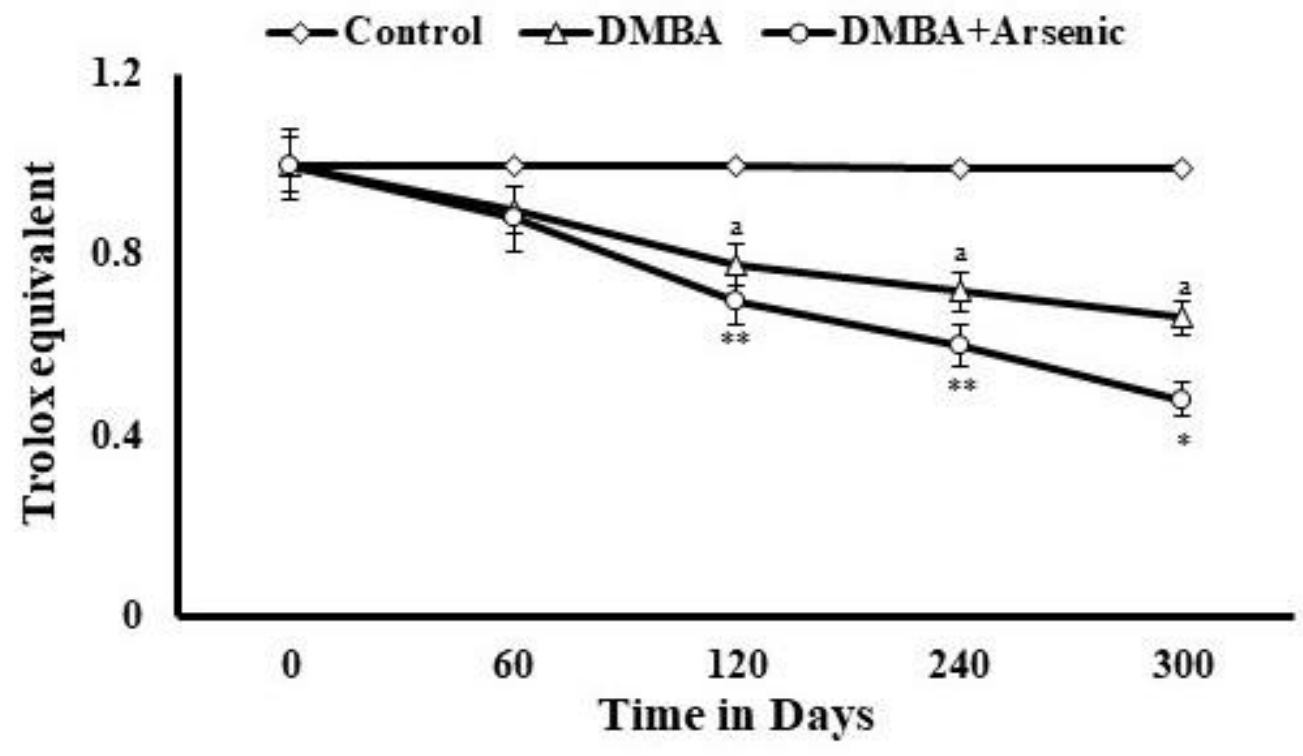

Figure 3

Fig.4 Modulation of Inflammatory status by DMBA, alone or in combination with iAs. Levels of cytokines, TNF- $\alpha$, IL-6, IL-17a, IL-22, NFkB (p50 and p65 subunits) as assessed by ELISA have been depicted as bar diagram. Values are mean of three independent experiments and are significant at ${ }^{a} \mathrm{p}<0.0001,{ }^{b} \mathrm{p}<0.005$ with respect to the control value. Further enhancement of Inflammatory status in presence of iAs, with respect to DMBA group alone is significant at $\mathrm{p}<0.0001$ and ${ }^{* *} \mathrm{p}<0.005$.

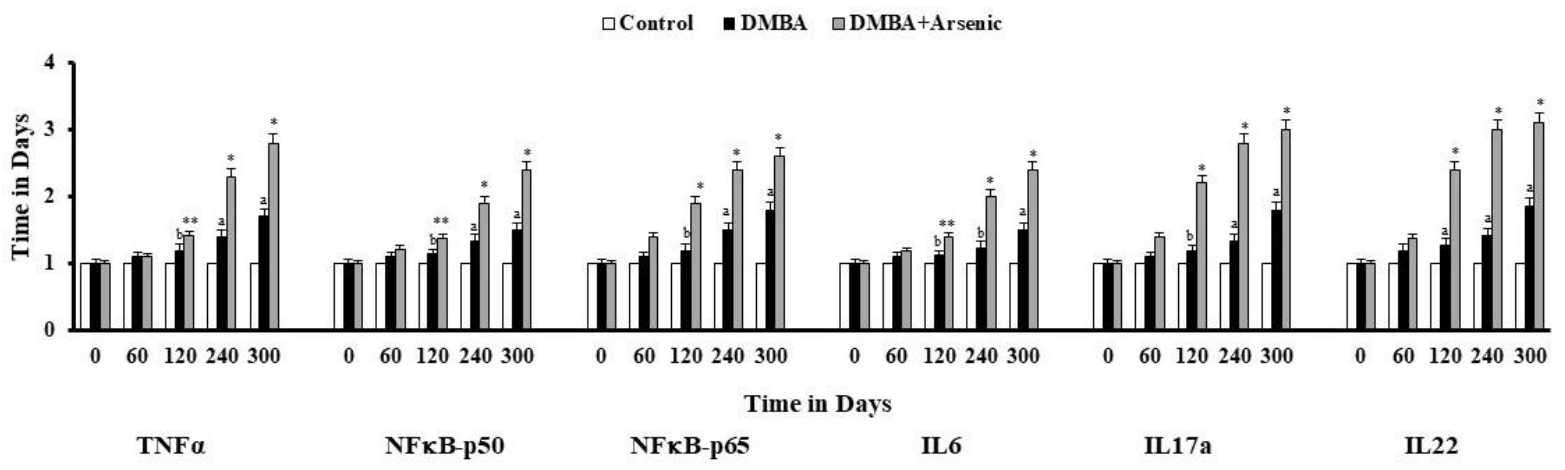


According to a study, iAs along with UV radiation caused greater oxidative damage in $\mathrm{HaCaT}$ cells in comparison to the carcinogen alone which hints that co-exposure of iAs with other DNA damaging agents lead to enhanced DNA damage, illustrating its co-carcinogenic ability (Zhou et al., 2021).

Excess ROS reacts with polyunsaturated fatty acids (PUFA) present in the lipid membranes and leads to production of malondialdehydes (MDA). MDAs are electrophilic in nature and react with other PUFA molecules, further generating more MDAs and other electrophilic products (Su et al., 2019). Cumulative effect of all these lipid-peroxidation products further enhances the effects of lipid membrane damage. Unquenched ROS also leads to alteration of protein functions by addition of carbonylated products to the amino acid side chains. It also results in splitting of the proteins and oxidation of few of its amino acids. These effects lead to increased redundancy of the proteins and accumulation of carbonylated products promoting modification of cellular homeostasis (Fedorova et al., 2014). iAs in the presence of DMBA has shown to elevate the protein carbonyl formation by many folds than that induced by DMBA alone. Prominent elevation of ROS generation, DNA damage, Lipid peroxidation and protein carbonyl formation by iAs in the presence of DMBA further supports the early development of carcinomas and its co-carcinogenic potential.

Antioxidants play an important role in quenching the excess ROS and thus prevent cellular damage. Studies from our laboratory indicate that iAs alone can play an important role in inhibiting the activities of various antioxidant enzymes, thus indirectly promoting further accumulation of ROS, leading to cancer (Biswas et al., 2010; Sinha et al., 2010). In the present study, it has been observed that, the total antioxidative capacity has been effectively reduced many folds in in presence of iAs. This may be the reason for early appearance of invasive carcinoma and the co-carcinogenic nature of iAs.

Chronic inflammatory condition is accepted to be a hallmark of cancer progression (Hanahan and Weinberg, 2011). iAs is known to promote chronic inflammation by inducing the secretion of pro-inflammatory cytokines like TNF- $\alpha$, IL-6 etc. Both epidemiological and animal experimentations have provided ample evidence regarding the pro-inflammatory nature of iAs (Singh et al., 2015; Prasad and Sinha, 2017). DMBA mediated skin carcinogenesis have been reported to induce the secretion of pro-inflammatory cytokines IL-17A and IL22 (Esser et al., 2013). The activities of the pro-inflammatory cytokines TNF- $\alpha$, IL-6, IL-17A and IL-22 have been found to be significantly higher in presence of iAs. These high generation of proinflammatory cytokines helps to maintain a chronic inflammatory condition, which is more prominent in presence of iAs.

$\mathrm{NF}-\kappa \mathrm{B}$, a transcription factor and downstream modulator of inflammatory pathways, plays an important role in the modulation of cell growth and cell proliferation. Induction of chronic inflammatory conditions promote translocation of the two subunits of $\mathrm{NF}-\kappa \mathrm{B}$, namely p50 and p65, into the nucleus (Hoesel and Schmid, 2013). It leads to alteration of cell proliferation pathways, promoting carcinogenesis. Present study indicates that the activity of p50 and p65 is highly enhanced by DMBA, and that in presence of As is even higher. NF- $\kappa \mathrm{B}$ activation by DMBA at 240 days was much higher in presence of iAs. This alteration of cell proliferation and growth hastens up carcinogenesis, thus reiterating the co-carcinogenic role of iAs.

The results of the present investigation clearly point out that iAs in the presence of DMBA is 
able to accelerate the process of carcinogenesis by inducing much higher ROS generation. As a consequence, DNA damage, lipid peroxidation and protein carbonyl content were elevated in presence of iAs. Besides, activation of pro-inflammatory cytokines and transcription factors are much escalated in comparison to DMBA treatment alone. Similarly, inhibition of antioxidative capacity by DMBA is much influenced in presence of iAs. All these findings suggest that presence of iAs may result in early appearance of carcinogenesis by DMBA.

\section{Acknowledgement}

Authors are indebted to Director, Chittaranjan National Cancer Institute (CNCI) for infrastructural facilities and financial support and $A G$ is indebted for his fellowship.

\section{References}

Abel, E. L., Angel, J. M., Kiguchi, K. and DiGiovanni, J. 2009. Multi-stage chemical carcinogenesis in mouse skin: fundamentals and applications. Nat Protoc. 4(9): 13501362.

Balasubramanyam, M., Koteswari, A. A., Kumar, R. S., Monickaraj, S. F., Maheswari, J. U. and Mohan, V. 2003. Curcumin-induced inhibition of cellular reactive oxygen species generation: novel therapeutic implications. J Biosci. 28(6): 715-721.

Belpomme, D., Irigaray, P., Hardell, L., Clapp, R., Montagnier, L., Epstein, S. and Sasco, A. J. 2007. The multitude and diversity of environmental carcinogens. Environ Res.105(3): 414-429.

Biswas, J., Roy, S., Mukherjee, S., Sinha, D. and Roy, M. 2010. Indian spice curcumin may be an effective strategy to combat the genotoxicity of arsenic in Swiss albino mice. Asian Pac J Cancer Prev. 11(1): 239247.

Esser, C., Bargen, I., Weighardt, H., HaarmannStemmann, T. and Krutmann, J. 2013. Functions of the aryl hydrocarbon receptor in the skin. Semin Immunopathol. 35(6):
677-691.

Fedorova, M., Bollineni, R. C. and Hoffmann, R. 2014. Protein carbonylation as a major hallmark of oxidative damage: update of analytical strategies. Mass Spectrom Rev. 33: 79-97.

Godschalk, R., Nair, J., van Schooten, F. J., Risch, A., Drings, P., Kayser, K., et al., 2002. Comparison of multiple DNA adduct types in tumor adjacent human lung tissue: effect of cigarette smoking. Carcinogenesis. 23(12): 2081-2086.

Hanahan, D. and Weinberg, R.A. 2011. Hallmarks of cancer: the next generation. Cell. 144: 646-674.

Hayes, J. D., Dinkova-Kostova, A. T., and Tew, K. D. 2020. Oxidative stress in cancer, Cancer Cell. 38: 167-197.

Hays, A. M., Srinivasan, D., Witten, M. L., Carter, D. E. and Lantz, R. C. 2006. Arsenic and cigarette smoke synergistically increase DNA oxidation in the lung. Toxicol Pathol. 34(4): 396-404.

Hoesel, B. and Schmid, J. A. 2013. The complexity of NF- $\kappa \mathrm{B}$ signalling in inflammation and cancer. Mol Cancer. 12(86).

Howe, C. G. and Gamble, M. V. 2016. Influence of Arsenic on Global Levels of Histone Posttranslational Modifications: a Review of the Literature and Challenges in the Field Curr Environ Health Rep. 3(3): 225237.

Hughes, M. F. 2002. Arsenic toxicity and potential mechanisms of action. Toxicol Lett. 133: 116.

Kinnula, V. L. 2005. Production and degradation of oxygen metabolites during inflammatory states in the human lung. Curr Drug Targets Inflamm Allergy. 4: 465-470.

Lawal, A. T. 2017. Polycyclic aromatic hydrocarbons. A review. Cogent Environ Sci. 3(1).

Mittal, M. and Flora, S. J. 2006. Effects of individual and combined exposure to sodium arsenite and sodium fluoride on tissue oxidative stress, arsenic and fluoride levels in male mice. Chem Biol Interact. 162(2): 128-139.

Ohkawa, H., Ohishi, N. and Yagi, K. 1979. Assay for lipid peroxides in animal tissues by 
thiobarbituric acid reaction. Anal Biochem. 95: 351-358.

Prasad, P. and Sinha, D. 2017. Low-level arsenic causes chronic inflammation and suppresses expression of phagocytic receptors. Environ Sci Pollut Res Int. 24(12):11708-11721.

Rao, C. V., Pal, S., Mohammed, A., Farooqui, M., Doescher, M. P., Asch, A. S., et al., 2017. Biological effects and epidemiological consequences of arsenic exposure, and reagents that can ameliorate arsenic damage in vivo. Oncotarget. 8(34): 57605-57621.

Roy, M., Sinha, D., Mukherjee, S. and Biswas, J. 2011. Curcumin prevents DNA damage and enhances the repair potential in a chronically arsenic-exposed human population in West Bengal, India. Eur $\mathbf{J}$ Cancer Prev. 20(2): 123-131.

Roy, M., Sinha, D., Mukherjee, S., Paul, S. and Bhattacharya, R. K. 2008. Protective effect of dietary phytochemicals against arsenite induced genotoxicity in mammalian V79 cells. Indian J Exp Biol. 46(10): 690-697.

Roy, P., Mukherjee, A. and Giri, S. 2016. Evaluation of genetic damage in tobacco and arsenic exposed population of Southern Assam, India using buccal cytome assay and comet assay. Ecotoxicol Environ Saf. 124: 169-176.

Rushton, L. 2003. How much does the environment contribute to cancer? Occup Environ Med. 60(2):150-156.

Samuel, S., Kathirvel, R., Jayavelu, T. and Chinnakkannu, P. 2005. Protein oxidative damage in arsenic induced rat brain: influence of dl- $\alpha$-lipoic acid. Toxicol. Lett. 155: 27-34.

Siddens, L. K., Larkin, A., Krueger, S. K.,
Bradfield, C. A., Waters, K. M., Tilton, S. C., et al., 2012. Polycyclic aromatic hydrocarbons as skin carcinogens: comparison of benzo[a]pyrene, dibenzo[p]chrysene and three environmental mixtures in the $\mathrm{FVB} / \mathrm{N}$ mouse. Toxicol Appl Pharmacol. 264(3): 377-386.

Singh, M. K., Yadav, S. S., Yadav, R. S., Chauhan, A., Katiyar, D. and Khattri, S. 2015. Protective effect of Emblicaofficinalis in arsenic induced biochemical alteration and inflammation in mice. Springerplus. 4: 438.

Singh, N. P., McCoy, M. T., Tice, R. R. and Schneider, E. L. 1988. A simple technique for quantitation of low levels of DNA damage in individual cells. Exp Cell Res. 175: 184-191.

Sinha, D., Roy, S. and Roy, M. 2010. Antioxidant potential of tea reduces arsenite induced oxidative stress in Swiss albino mice. Food Chem Toxicol. 48(4): 1032-1039.

Su, L. J., Zhang, J. H., Gomez, H., Murugan, R., Hong, X., Xu, D., et al., 2019. Reactive Oxygen Species-Induced Lipid Peroxidation in Apoptosis, Autophagy, and Ferroptosis. Oxid Med Cell Longev. 2019: 5080843.

Yao, P. L., Lin, Y. C., Wang, C. H., Huang, Y. C., Liao, W. Y., Wang, S. S., et al., 2005. Autocrine and paracrine regulation of interleukin-expression in lung cancer cells. Am J Respir Cell Mol Biol. 32: 540-547.

Zhou, X., Speer, R. M., Volk, L., Hudson, L. G. and Liu, K. J. 2021. Arsenic cocarcinogenesis: Inhibition of DNA repair and interaction with zinc finger proteins. Semin Cancer Biol. S1044-579X(21): 00137-1.

\section{How to cite this article:}

Archismaan Ghosh, Sutapa Mukherjee and Madhumita Roy. 2021. Co-Carcinogenicity of Arsenic: Probable Mechanisms. Int.J.Curr.Microbiol.App.Sci. 10(11): 294-305. doi: https://doi.org/10.20546/ijcmas.2021.1011.033 